\title{
Reference values for alveolar membrane diffusion capacity and pulmonary capillary blood volume
}

\author{
P. Zanen*, I. van der Lee*, T. van der Mark\#, J.M.M. van den Bosch*
}

Reference values for alveolar membrane diffusion capacity and pulmonary capillary blood volume. P. Zanen, I. van der Lee, T. van der Mark, J.M.M. van den Bosch. (C) ERS Journals Ltd 2001.

ABSTRACT: The reference values for diffusion capacity of the alveolar capillary membrane $(T \mathrm{~m}, \mathrm{CO})$ and pulmonary capillary volume $\left(Q_{\mathrm{c}}\right)$ are scarce, while the standard deviations of the equations are large. New equations and residual standard deviations (RSDs) were determined in a sample of healthy subjects.

$T \mathrm{~m}, \mathrm{CO}$ and $Q_{\mathrm{c}}$ values were measured in 117 ( 72 females, 45 males) nonsmoking healthy subjects. The carbon monoxide transfer factor $(T \mathrm{~L}, \mathrm{CO})$ was determined when the volunteer was breathing room air and subsequently, when the volunteer was breathing $100 \%$ oxygen. From these data, $T \mathrm{~m}, \mathrm{CO}$ and $Q_{\mathrm{c}}$ values were calculated.

The females' $T \mathrm{~L}, \mathrm{CO}$ was $3.15 \mathrm{mmol} \cdot \mathrm{min}^{-1} \cdot \mathrm{kPa}^{-1}$ lower than the males', apparently caused by lower female lung volume. $T \mathrm{~m}, \mathrm{CO}$ and $Q_{\mathrm{c}}$ were lower in females, but correction for lung volume eliminated this difference. $Q^{-1}$ reference equations for females and males, respectively, are $4.375 \times 10^{-2}-1.085 \times 10^{-2} \times$ height and $4.455 \times 10^{-2}$ $1.085 \times 10^{-2} \times$ height (RSD for both sexes: $2.544 \times 10^{-3}$ ). $\mathrm{Tm}_{\mathrm{m}} \mathrm{Co}^{-1}$ reference equations for females and males, respectively, are $0.111+3.304 \times 10^{-4} \times$ age- $-4.753 \times 10^{-2} \times$ height and $0.127+3.304 \times 10^{-4} \times$ age $-4.753 \times 10^{-2} \times$ height (RSD for both sexes: $1.085 \times 10^{-2}$ ). The general character of these equations complies with earlier publications, the only difference being that the RSDs are 1.18-2.76 times lower.

New reference equations for diffusion capacity of the alveolar capillary membrane and pulmonary capillary volume are available with considerably smaller residual standard deviations.

Eur Respir J 2001; 18: 764-769.

Measurement of the single-breath carbon monoxide (CO) transfer factor $(T \mathrm{~L}, \mathrm{CO})$ to determine the quality of gas transfer is presently a standard procedure. The transfer of $\mathrm{CO}$ over the alveolar capillary membrane is governed by two resistances in series: the resistance of the membrane itself (the physical resistance $(R \mathrm{~m})$ ) and the capillary resistance ( $R$ cap): $R=R \mathrm{~m}+R$ Cap. The latter resistance is believed to be influenced by the pulmonary capillary blood volume $(Q \mathrm{c})$, through the binding of $\mathrm{CO}$ to haemoglobin and the transfer/transport of $\mathrm{CO}$ into the red blood cell (the latter two presented by the chemical resistance, the $\mathrm{CO}$ reaction rate coefficient in red blood cells $(\theta \mathrm{CO}))$. The chemical resistance depends on the red blood cell oxygen $\left(\mathrm{O}_{2}\right)$ concentration. It is customary to present the terms in $R=$ $R \mathrm{~m}+R$ cap by their reciprocals (conductances) and arrive at the well-known Roughton-Forster equation [1], which describes the two-resistor model for $\mathrm{CO}$ transfer:

$$
\frac{1}{T_{\mathrm{L}, \mathrm{CO}}}=\frac{1}{T_{\mathrm{m}, \mathrm{CO}}}+\frac{1}{\theta_{\mathrm{CO}} Q_{\mathrm{c}}}
$$

where $T \mathrm{~m}, \mathrm{CO}$ denotes the diffusion capacity of the alveolocapillary membrane. By modifying the inspired $\mathrm{O}_{2}$ concentration, the terms $T \mathrm{~m}, \mathrm{CO}$ and $Q_{\mathrm{c}}$ in Equation 1 can be determined.

In order to put measurements of these variables into
*Dept of Pulmonary Diseases, St Antonius Hospital, Nieuwegein, and ${ }^{\#}$ Dept of Pulmonary Diseases, University Hospital Groningen, Groningen, the Netherlands.

Correspondence: P. Zanen

Dept of Pulmonary Diseases

St Antonius Hospital

Koekoekslaan 1

Nieuwegein

The Netherlands

Fax: 31306052001

Keywords: Membrane diffusion pulmonary capillary volume reference values

Received: March 282001

Accepted after revision June 302001 clinical use, a comparison between the measured values and reference values is needed to determine the severity of the disease process [2]. When comparing actual with predicted values, the use of standardized residuals is recommended. References values for the two components of the transfer factor and their standard deviations (SD) are scarce; only the values of Cotes [3] and Frans [4] are widely available, but the derivation of these values is not extensively described (the equations of COTES [3] are listed in his book as "not published"). The reference values of CRAPO et al. [5] were determined using a rebreathing technique, which differs from the more commonly used singlebreath technique. The aim of the present study is to provide reference values and the corresponding residual standard deviations (RSDs) for $1 / T \mathrm{~m}$ and $1 / Q_{\mathrm{c}}$, derived from measurements in a cohort of healthy volunteers.

\section{Materials and methods}

\section{Subjects}

One-hundred and seventeen (72 females, 45 males) nonsmoking healthy subjects were invited to participate in this study. They were recruited from the 
nursing, administrative and laboratory staff of the hospital; all had sedentary jobs without physical strain and lived in an area without heavy traffic and/or air pollution. All subjects gave verbal and written consent to participate. The Medical Ethical Committee of the hospital approved the study.

Upon questioning and physical examination, all volunteers were found to be without complaints or disease. Pregnancy was an exclusion criterion because of the possible changes in (pulmonary) haemodynamics. No special attention was paid to the menstrual cycle. A stringent inclusion criterion was a normal haemoglobin level. The normal values in this hospital ranged from 7.7-9.6 mM for females and from $8.6-10.7 \mathrm{mM}$ for males. The demographic data and mean lung function are presented in table 1 .

\section{Measurements}

First, the single breath $T \mathrm{~L}, \mathrm{CO}$ was determined when the volunteer was breathing room air with $21 \% \mathrm{O}_{2}$ $(T \mathrm{~L}$, low) and, subsequently, the same was done when the volunteer was breathing $100 \% \mathrm{O}_{2}$ (TL,high) [6]. Using the equation:

$$
\frac{1}{\theta_{\mathrm{CO}}}=\left(0.001+0.000134 P_{\mathrm{c}, \mathrm{O}_{2}}\right)
$$

the $\theta \mathrm{CO}$ value for the $21 \%$ and $100 \% \mathrm{O}_{2}$ situation was calculated [3], where $P_{\mathrm{c}}, \mathrm{O}_{2}$ is the mean capillary $\mathrm{O}_{2}$ tension, which is estimated from the alveolar $\mathrm{O}_{2}$ tension $\left(\mathrm{PA}, \mathrm{O}_{2}\right)$, the $\mathrm{O}_{2}$ consumption and diffusing capacity (rendering $\mathrm{Pc}_{\mathrm{c}} \mathrm{O}_{2}$ slightly lower than $\mathrm{PA}_{2} \mathrm{O}_{2}$ ). The $\mathrm{PA}, \mathrm{O}_{2}$ was measured in the exhaled alveolar sample and not by using the alveolar air equation. The latter could produce incorrect results because the inhaled fraction $\mathrm{O}_{2}$ is changed due to the presence of helium $(\mathrm{He})$ and $\mathrm{CO}[3,6]$. The term 0.001 in Equation 2 is based on a partition coefficient of 2.5. The following equations used to calculate $Q_{\mathrm{c}}$ and $T \mathrm{~m}$ can be derived from Equation 1 by algebraic manipulation of the high and low $\mathrm{O}_{2}$ expressions of this equation:

$$
Q_{\mathrm{c}}=\frac{\frac{1}{\theta \text { high }}-\frac{1}{\theta_{\text {low }}}}{\frac{1}{T_{\mathrm{L}, \text { high }}}-\frac{1}{T_{\mathrm{L}, \mathrm{low}}}}
$$

Table 1.-Demographic and lung function data on the male and female subjects

\begin{tabular}{lcc}
\hline Variable & Males & Females \\
\hline Age yrs & $40.1 \pm 10.8$ & $38.3 \pm 11.5$ \\
Weight kg & $82.6 \pm 11.8$ & $66.0 \pm 8.8$ \\
BMI & $24.7 \pm 2.9$ & $23.1 \pm 3.1$ \\
Height m & $1.83 \pm 0.07$ & $1.69 \pm 0.06$ \\
FEV $\%$ pred & $112.0 \pm 12.7$ & $111.2 \pm 13.8$ \\
TLC \% pred & $108.3 \pm 10.8$ & $110.3 \pm 12.3$ \\
VA/TLC \% & $97 \pm 5$ & $94 \pm 4$ \\
\hline
\end{tabular}

Data are presented as mean \pm SD. BMI: body mass index; FEV1: forced expiratory volume in one second; TLC: total lung capacity; $V$ A: alveolar volume. $V$ A was obtained using single-breath helium dilution and TLC via body plethysmography. and

$$
T_{\mathrm{m}}=\frac{1}{\frac{1}{T \mathrm{~L}, \mathrm{low}}-\frac{1}{\theta_{\text {low }} Q_{\mathrm{c}}}}
$$

where $\theta$ high and $\theta$ low are the $\mathrm{CO}$ reaction rate coefficients under $100 \%$ and $21 \% \mathrm{O}_{2}$ conditions, respectively.

Estimations of $1 / Q_{\mathrm{c}}$ and $1 / T \mathrm{~m}, \mathrm{CO}$ were made using a Jaeger Compact Lab Transfer system (Erich Jaeger GmbH, Wuerzburg, Germany).

After a rest (in which the questioning and physical examination took place), all volunteers inhaled a test gas containing $0.25 \% \mathrm{CO}, 9 \% \mathrm{He}$ and balance air, while their lungs were filled with room air. They inhaled the test gas from residual volume up to total lung capacity (TLC) level in the shortest possible time $(<2.5 \mathrm{~s})$, and subsequently held their breath for $10 \mathrm{~s}$ after which they exhaled quickly into a sample bag. The breath-hold period was calculated starting from two-thirds of the way through inspiration time and ending half way through the sample collection. The first portion of the exhaled volume $(800 \mathrm{~mL})$ containing the dead space $(300 \mathrm{~mL}$ in total) was discarded and only the alveolar fraction was sampled (sample volume $800 \mathrm{~mL}$ ). From this sample bag, the exhaled fraction of $\mathrm{CO}$ and $\mathrm{He}$ was determined. This procedure was performed in triplicate.

The next step was to inhale $100 \% \mathrm{O}_{2}$ for a period long enough to stabilize the exhaled $\mathrm{O}_{2}$ at the high level of $95 \%$. The exhaled $\mathrm{O}_{2}$ fraction was monitored breath-bybreath and the $T \mathrm{~L}, \mathrm{CO}$ measurement only started when the exhaled fraction became stable for $\geqslant 60 \mathrm{~s}$. RoTHEN et al. [7] found that after $40 \mathrm{~min}$ of $100 \% \mathrm{O}_{2}$ breathing, the total atelectasis volume was $4.2 \pm 4.5 \mathrm{~cm}^{2}$, compared to $1.6 \pm 1.6 \mathrm{~cm}^{2}$ when breathing room air. As a result of this, and because the repeated vital capacity manoeuvres inhibit atelectasis formations, significant atelectasis is improbable here. Without disconnecting the volunteer from the apparatus, a test gas containing $0.25 \% \mathrm{CO}, 7.7 \%$ $\mathrm{He}$ and balance $100 \% \mathrm{O}_{2}$ was inhaled from residual volume up to TLC level. The rest of this procedure was identical to the one described above and was also performed in triplicate. Thus, in total six determinations took place, which did not result in a build-up of significant carboxyhaemoglobin $(\mathrm{COHb})$ levels $( \pm 3 \% \mathrm{COHb})$.

The values for $T \mathrm{~L}, \mathrm{CO}$ under room air and $100 \% \mathrm{O}_{2}$ conditions were averaged and used for the calculation of $1 / Q_{\mathrm{c}}$, and $(1 / T \mathrm{~m}, \mathrm{CO}) \times\left(1 / Q_{\mathrm{c}}\right)$ is expressed $\mathrm{mL}^{-1}$ and $1 / T \mathrm{~m}, \mathrm{CO}$ as $\mathrm{mmol}^{-1} \cdot \mathrm{min} \cdot \mathrm{kPa}$. No correction was made for haemoglobin $(\mathrm{Hb})$ levels. STAm et al. [8] showed that in healthy volunteers with normal Hb levels, correction has only a very limited effect. The distribution of the $\mathrm{Hb}$ levels is narrower than that of $1 / Q_{\mathrm{c}}$ and $1 / T \mathrm{~m}, \mathrm{CO}$ and no variance reduction of the latter two is possible.

$\mathrm{CO}$ gas was analysed by means of infrared absorbance and $\mathrm{He}$ by thermal conductivity (He analysis was corrected for high $\mathrm{O}_{2}$ tensions). Before each measurement, both analysers were calibrated using certified gas mixtures.

\section{Analysis}

Biological data are frequently lognormally distributed, so the measured $1 / Q_{\mathrm{c}}$ and $1 / T_{\mathrm{m}, \mathrm{CO}}$ values were 
a)

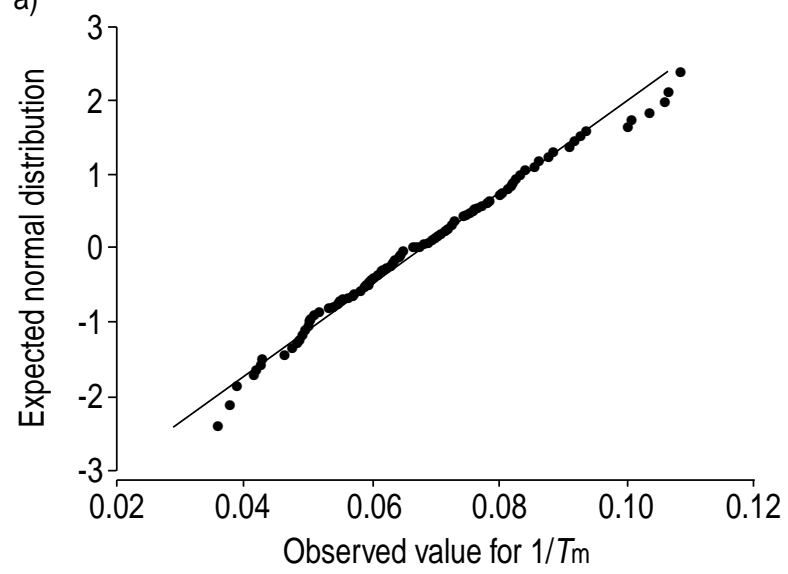

b)

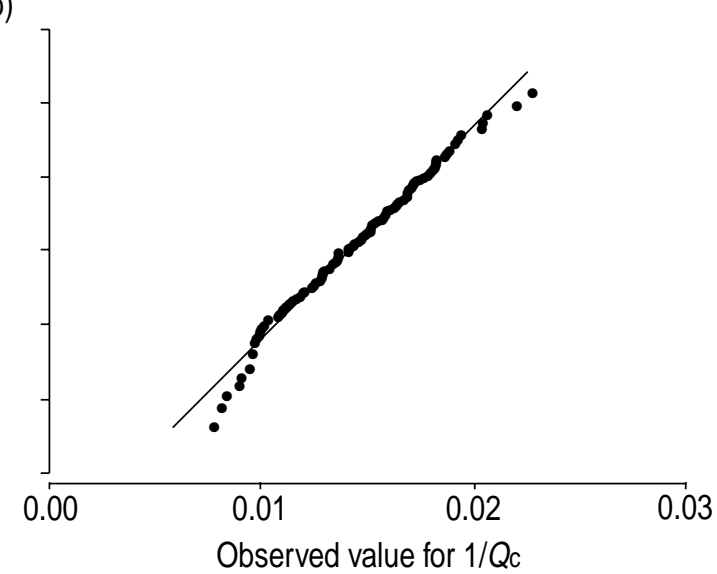

Fig. 1. - Distribution of the a) $1 / T \mathrm{~m}, \mathrm{CO}$ and b) $1 / Q_{\mathrm{c}}$ values. The straight lines in these graphs represent the normal distribution. The values show a close overlap with the normal distribution in both cases. $T \mathrm{~m}, \mathrm{CO}$ : diffusion capacity of the alveolar capillary membrane; $Q_{\mathrm{c}}$ : pulmonary capillary volume.

subjected to a Kolmogorov-Smirnov test to examine deviations from the normal distribution. The $1 / Q \mathrm{c}$ and $1 / T_{\mathrm{m}}, \mathrm{CO}$ values were averaged and the \pm 2 SD range was calculated. To estimate possible differences between males and females, the data were subjected to analysis of (co)variance to explain the influence of covariates.

The $1 / Q_{\mathrm{c}}$ and $1 / T \mathrm{~m}, \mathrm{CO}$ values were incorporated into a general linear model analysis of (co)variance, which has the same outcome as the classical multiple regression analysis approach. The independent variables were sex, age, height and the interaction between sex and age/height. The latter two test for parallelism in regression slopes and determine whether the male/ female regression slopes for age and height differ. If they do not differ, the slopes can be pooled. Incorporation of a multitude of (irrelevant) variables weakens the predictive power of any regression model; useful variables show high correlations with $1 / Q_{\mathrm{c}}$ and $1 / T \mathrm{~m}, \mathrm{CO}$, but low intercorrelations.

Spearmann's correlation coefficients were calculated to determine the relationships between the independent variables. Significance levels were set at $\alpha=0.05$ and all data are represented as mean \pm SD.

\section{Results}

The single-breath $T \mathrm{~L}, \mathrm{CO}$ values on room air are expressed as a percentage of predicted [9]. The female group showed a small, but significant departure from the expected value: $90 \pm 14.2 \%$ pred $(\mathrm{p}<0.001)$. No significant departure was found for males: $99 \pm 14.1 \%$ pred $(\mathrm{p}=0.638)$. Males showed a higher transfer factor than females $(\mathrm{p}=0.002)$, with a mean difference of $3.15 \mathrm{mmol} \cdot \mathrm{min}^{-1} \cdot \mathrm{kPa}^{-1}(95 \%$ confidence interval (CI) of the difference 3.77-2.52).

The Kolmogorov-Smirnov test indicated no significant deviation from the normal distribution for $1 / Q \mathrm{c}$ and $1 / T \mathrm{~m}, \mathrm{CO}$ values $(\mathrm{p}=0.2)$ (fig. 1$)$.

The analysis of variance of $1 / Q_{\mathrm{c}}$ and $1 / T \mathrm{~m}, \mathrm{CO}$ values showed significant sex differences $(p=0.011$ and $p<$ 0.001 , respectively), even after correction for height and age. The mean and \pm 2 SD ranges for $1 / Q_{\mathrm{c}}$ and $1 / T \mathrm{~m}, \mathrm{CO}$ in females and males are shown in table 2. The interactions between sex and height/age were nonsignificant ( $\mathrm{p}>0.063$ in all cases), indicating that the regression slopes for age and height do not differ between males and females.

In table 3 , the correlation coefficients between $1 / Q \mathrm{c}$, $1 / T \mathrm{~m}, \mathrm{CO}$ and the other lung function parameters are shown. They are significantly correlated with height, forced expiratory volume in one second (FEV1), TLC and residual volume. These variables are, therefore, possible candidates for use in regression analysis. However, the correlation between height on the one hand and FEV1, TLC and residual volume on the other was also highly significant, thus rendering them less suitable [10]. As a result of this, and in order to be able to compare the outcome to earlier approaches $[3,4]$, only height and age were included in the analysis.

Table 2.-Descriptive summary of $1 / Q_{c}$ and $1 / T \mathrm{~m}$, co levels in healthy males and females

\begin{tabular}{lcc}
\hline Sex & $1 / Q \mathrm{c} \mathrm{mL}^{-1}$ & $1 / T \mathrm{~m}, \mathrm{CO}^{\mathrm{mmol}}{ }^{-1} \cdot \mathrm{min} \cdot \mathrm{kPa}$ \\
\hline Females & & \\
$\quad$ Mean \pm SD & $1.583 \times 10^{-2} \pm 3.082 \times 10^{-3}$ & $7.613 \times 10^{-2} \pm 1.345 \times 10^{-2}$ \\
\pm 2 SD range & $9.666 \times 10^{-3}-2.199 \times 10^{-2}$ & $4.923 \times 10^{-2}-1.030 \times 10^{-1}$ \\
Males & & \\
$\quad$ Mean \pm SD & $1.159 \times 10^{-2} \pm 2.260 \times 10^{-3}$ & $5.418 \times 10^{-2} \pm 9.624 \times 10^{-3}$ \\
\pm 2 SD range & $7.073 \times 10^{-3}-1.611 \times 10^{-2}$ & $3.493 \times 10^{-2}-7.343 \times 10^{-2}$ \\
\hline
\end{tabular}

$Q$ c: pulmonary capillary blood volume; $T \mathrm{~m}, \mathrm{CO}$ : diffusion capacity of the alveolar capillary membrane. 
Table 3.-Correlation coefficient matrix of $1 / T \mathrm{~m}, \mathrm{CO}$ and $1 / Q_{c}$ with age, height, forced expiratory volume in one second $\left(F E V_{1}\right)$, total lung capacity (TLC) and residual volume

\begin{tabular}{llllll}
\hline & Age & Height & FEV1 & TLC & $\begin{array}{c}\text { Residual } \\
\text { volume }\end{array}$ \\
\hline $1 / T_{\mathrm{m}, \mathrm{CO}}$ & $0.208^{*}$ & $-0.678^{* *}$ & $-0.773^{* *}$ & $-0.743^{* *}$ & $-0.264^{* *}$ \\
$1 / Q_{\mathrm{c}}$ & 0.055 & $-0.687^{* *}$ & $-0.699^{* *}$ & $-0.755^{* *}$ & $-0.401^{* *}$ \\
\hline
\end{tabular}

$T \mathrm{~m}, \mathrm{CO}$ : diffusion capacity of the alveolar capillary membrane; $Q_{\mathrm{c}}$ : pulmonary capillary blood volume. *: correlation is significant at 0.05 level; **: correlation is significant at 0.01 level.

The derived equations for $1 / Q_{\mathrm{c}}$ and $T \mathrm{~m}, \mathrm{CO}$ are listed in tables 4 and 5 together with those of CoTEs [3] and Frans [4]. Significant predictors for $1 / T \mathrm{~m}, \mathrm{CO}$ were age $(p=0.001)$ and height $(p=0.005)$, but only height was a significant predictor for $1 / Q_{\mathrm{c}}(\mathrm{p}<0.001)$. The RSDs are 1.18-2.76 times lower than those of Cotes [3] and FRANS [4], indicating a significantly higher power to detect deviations from the normal values.

Cotes [3] listed a value for $T \mathrm{~m} / Q_{\mathrm{c}}$ of 0.2 . The present authors found a similar value of $0.21 \pm 0.035$, while no significant difference was found between females and males $(\mathrm{p}=0.4)$.

\section{Discussion}

In the present study, reference equations for $1 / Q_{c}$ and $1 / T \mathrm{~m}, \mathrm{CO}$ have been determined in a sample of healthy subjects. There are striking similarities with two previous approaches, but the major difference is the smaller RSDs and hence, the higher sensitivity to detect disease. Height has the same influence in all approaches; taller people show smaller $1 / Q_{\mathrm{c}}$ and $1 / T \mathrm{~m}, \mathrm{CO}$ values, which means that $Q_{\mathrm{c}}$ and $T \mathrm{~m}, \mathrm{CO}$ values increase with increasing height. With regard

Table 4.-Regression equations for $1 / Q_{c}$ in males and females

\begin{tabular}{|c|c|c|}
\hline Sex & Regression equation & RSD \\
\hline Females $^{\#}$ & $4.375 \times 10^{-2}-1.805 \times 10^{-2} \times$ height & $2.544 \times 10^{-3}$ \\
\hline Males \# & $4.455 \times 10^{-2}-1.805 \times 10^{-2} \times$ height & \\
\hline Females & $6.1 \times 10^{-2}-2.74 \times 10^{-2} \times$ height & $6 \times 10^{-3}$ \\
\hline Males & $4.7 \times 10^{-2}-2.01 \times 10^{-2} \times$ height & $3 \times 10^{-3}$ \\
\hline
\end{tabular}

$Q$ c: pulmonary capillary volume; RSD: residual standard deviation. ${ }^{\#}$ : contains the equations derived in the present study; `: contains equations derived in studies of COTES [3] (females) and FRANS [4] (males). Height is in metres.
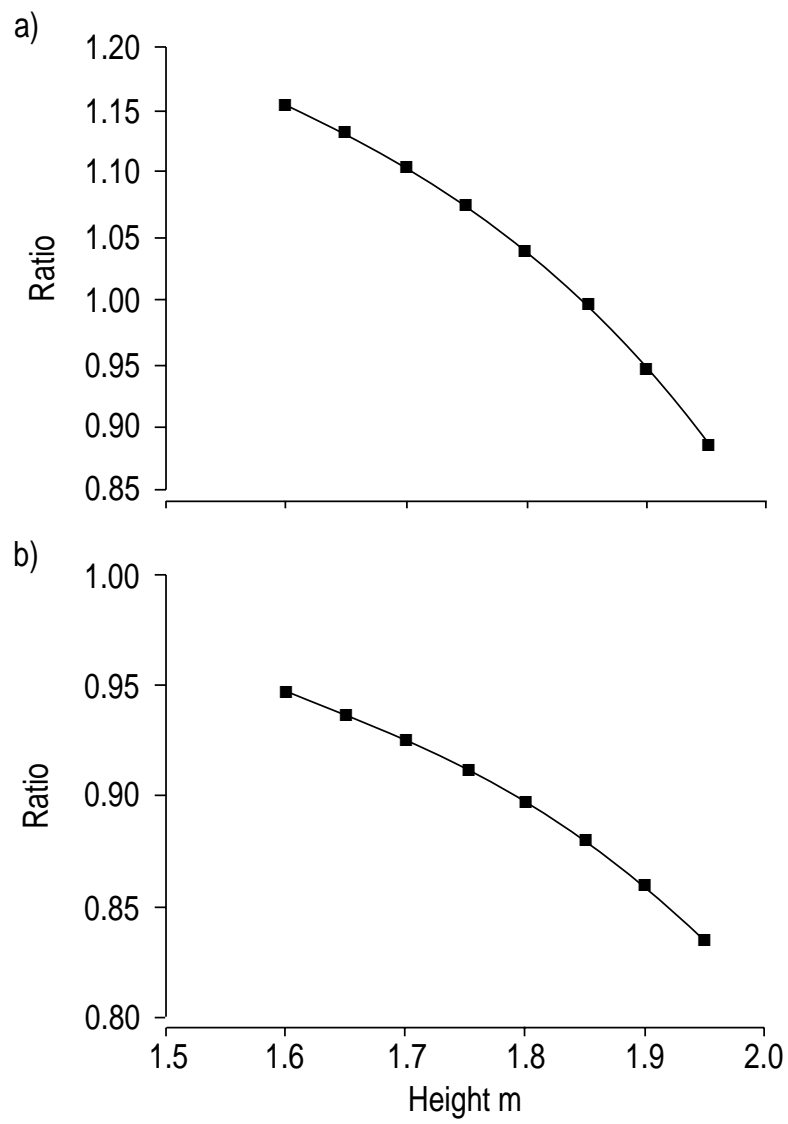

Fig. 2.-Ratio of predicted values for $1 / Q_{\mathrm{c}}$ in a) females and b) males derived from the present study, and those of COTES [3] and FRANS [4]. The ratio depicts the predicted values of COTES [3] and FRANS [4] divided by those of the current study. Only one line is present because an age factor is not included. $Q_{\mathrm{c}}$ : pulmonary capillary volume.

to age, in the equations for $1 / T_{\mathrm{m}} \mathrm{CO}$, positive terms were found, meaning that $T \mathrm{~m}, \mathrm{CO}$ decreases as one gets older. It must be noted that in all equations, the influence of age is much smaller than that of height, so the significance of these differences is limited. A significant influence of age for $1 / Q_{\mathrm{c}}$ is lacking in all approaches. Systematic differences in the predicted values are present due to differences in the regression coefficients and constants. The predicted $1 / Q_{\text {c }}$ value derived from this study is smaller in short females and larger in taller females. The "break-even point" is at a height of $1.85 \mathrm{~m}$, so in the majority of female subjects the authors predict smaller values. For male $1 / Q \mathrm{c}$, the authors always predict smaller values, so it can be estimated that $Q \mathrm{c}$ is always larger than estimations of earlier equations (fig. 2).

Table 5. - Regression equations for $1 / T \mathrm{~m}, \mathrm{co}$ in males and females

\begin{tabular}{lcr}
\hline Sex & Regression equation & RSD \\
\hline Females $^{\#}$ & $0.111+3.304 \times 10^{-4} \times$ age- $4.753 \times 10^{-2} \times$ height & $1.085 \times 10^{-2}$ \\
Males $^{\text {Males and females }}$ & $0.127+3.304 \times 10^{-4} \times$ age- $4.753 \times 10^{-2} \times$ height \\
\end{tabular}

$T \mathrm{~m}, \mathrm{CO}$ : diffusion capacity of the alveolar capillary volume; RSD: residual standard deviation. * : contain equations derived in the present study; " contains equations derived in the study of COTES [3]. Height is in metres and age in years. 
a)

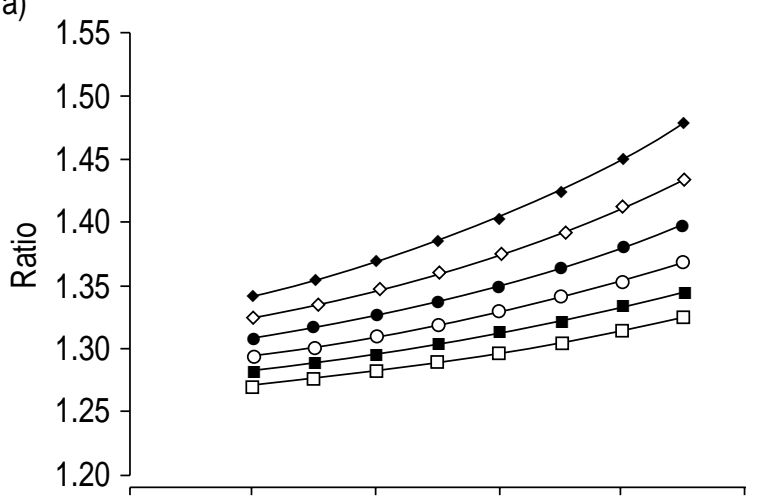

b)



Fig. 3. - Ratio of predicted values for $1 / T \mathrm{~m}, \mathrm{CO}$ in a) females and b) males derived from the present study and that of COTES [3]. The ratio depicts the predicted values of COTES [3] divided by those of the present study. The lines are broken down by age. $\$: 20 \mathrm{yrs}$; $\diamond: 30$ yrs; ๑: 40 yrs; $\bigcirc: 50$ yrs; $\square: 60$ yrs; $\square: 70$ yrs. $T \mathrm{~m}, \mathrm{CO}$ : diffusion capacity of the alveolar capillary membrane.

For $1 / T \mathrm{~m}, \mathrm{CO}$, it is evident that the female constant in the equation of CoTEs [3] is larger, as it is in the present study, while this study's height factor is smaller. Thus, the authors predict smaller female estimates for $1 / T \mathrm{~m}, \mathrm{CO}$ (=larger $T \mathrm{~m}, \mathrm{CO}$ values). In males, the picture is reversed; larger "Cotes" values for $1 / T \mathrm{~m}, \mathrm{CO}$ (=smaller $T \mathrm{~m}, \mathrm{CO}$ values). The differences become stronger for taller male/female subjects (fig. 3).

Because information on the subjects and/or experimental set-up used by CoTEs [3] and FrANs [4] is only partially available, it is rather difficult to explain these differences. However, several factors can be ruled out. First, a systemic deviation due to the equipment or experimental procedures used is unlikely. When such systemic equipment differences were to blame, the deviations between the present equations and those of Cotes [3] and Frans [4] would be constant both in males and females, which is not the case. It is also very unlikely that physiological and/or anatomical differences are responsible. It is hard to argue that the alveolar capillary membrane structure in the volunteers in these studies would have been (very) different. This would imply that different types of people exist. To underline this argument, the authors point to the similar $T \mathrm{~m} / Q$ c ratio, which must lead to the conclusion that the contribution of the alveolar and capillary resistance to the total transfer resistance is identical, indicating similar anatomy and/or physiology in all volunteers.

Alveolar volume ( $V$ A) plays an important role, although the exact influence on TL,CO is still under debate $[8,11,12]$. It, therefore, seems plausible that when a sample of short subjects is selected, lower $T \mathrm{~m}, \mathrm{CO}$ and $Q \mathrm{c}$ values will be measured and another set of regression equations will follow. In regression analysis, when the mean of a variable increases or decreases (keeping the width of the distribution the same), the constant of the regression equation will change but the coefficients will not. When the width of a distribution increases, it means that more extreme values are present, and regression analysis is sensitive to these values, especially when the sample is rather small. In theory, a few extreme values can profoundly change the entire picture. Thus, differences in $V \mathrm{~A}$, or the distribution of it, might serve as an explanation for the differences between these and previous equations.

A major difference between the equations from this and previous studies is the magnitude of the RSD, which is a factor 1.18-2.76 lower. The latter is used to calculate the $95 \%$ CIs, which are used to decide whether or not a measured value is within the normal range. It is clear that the reduction of the RSDs will render the assessment of measured values more sensitive because the lower or upper end of the $95 \%$ CI lies closer to the predicted value. The smaller SD values are the direct result of a reduced heterogeneity in the sample, they probably result from a lack of extreme values and/or experimental errors. The SD estimate in a smaller sample, however, is more sensitive to a (few) outliers than a larger sample. As previously mentioned, regression analysis is particularly sensitive for outliers. The authors checked for and found no evidence of influencing outliers (data not shown), hence the equations and RSDs are trusted not to be biased by outliers. The role of experimental error will be clear.

The $1 / T \mathrm{~m}, \mathrm{CO}$ values measured show a sex difference that is not present in the equations of CoTES [3]. However, a sex difference should be expected. There is a general consensus that TL,CO differs in females and males and reference equations reflect this. $T \mathrm{~L}, \mathrm{CO}$ is influenced by the membrane and capillary resistance and when $T \mathrm{~m}, \mathrm{CO}$ does not exert a sex effect, the $T \mathrm{~L}, \mathrm{CO}$ sex difference must be caused solely by the capillary resistance. When variance due to a sex difference is not accounted for, it will be added to nonexplained variance and the RSD will increase. In the present study's equations, the sex difference is present as different regression constants and it could be argued that because they are rather close they should be pooled. Regression equations must accurately reflect the characteristics of the subjects (e.g. a significant sex difference in the present study). Pooling estimated variables when small or nonsignificant differences are found is not a good option because it is a decision influenced by the accuracy of the regression process. Taking this option may cause differences that are still clinically important to be ignored.

Because $V$ A plays an important role, the diffusing capacity makes it an attractive covariate to include in 
reference equations. CHINN et al. [11] showed that the inclusion of $V$ A divided by height $(\mathrm{H})$ squared $\left(V \mathrm{~A} \cdot \mathrm{H}^{-2}\right)$ lowers RSDs considerably. However, when a $V$ A term appears in a reference equation, the diffusion parameters corrected for $V \mathrm{~A}$, which results in $T \mathrm{~m}, \mathrm{CO}$ or $Q \mathrm{c}$ per litre $V$ A can be obtained. The first of the two parameters serves the same purpose as the well-known KCO $(=T \mathrm{~L}, \mathrm{CO} / V \mathrm{~A})$. It is not so much a question of whether $V \mathrm{~A}$ is a better parameter than height or age, but its inclusion would result in a new and different parameter. $T \mathrm{~m}, \mathrm{CO} / V \mathrm{~A}, Q \mathrm{~d} / V \mathrm{~A}$ or $T \mathrm{~m}, \mathrm{CO} / V \mathrm{~A} \cdot \mathrm{H}^{-2}, Q_{\mathrm{d}} / V \mathrm{~A} \cdot \mathrm{H}^{-2}$ are not, at present, routinely used. More research is needed to select the best parameter and to design a proper evaluation scheme (especially for $Q_{\mathrm{c}}$ ).

The Roughton-Forster equation [1] depends on a correct calculation of the $\theta \mathrm{CO}$ parameter, and the proper value of this parameter still raises much discussion. FORSTER [13] highlighted the basic assumption that the $P \mathrm{~A}, \mathrm{O}_{2}$ should at least be $>20 \mathrm{kPa}$ $(>150 \mathrm{mmHg})$ to obtain a proper $\theta \mathrm{CO}$ value, although at the same time admitted that the errors introduced by using lower $\mathrm{O}_{2}$ levels are small. Mistakes made in the determination of $\theta \mathrm{CO}$ will render $1 / Q_{\mathrm{c}}$ and $1 / T \mathrm{~m}, \mathrm{CO}$ estimates invalid. This study was not designed to validate the approach of RoUGHTON and ForSTER [1], but experiments in which the nitric oxide (NO)-CO method was used to determine $1 / Q_{\mathrm{c}}$ and $1 / T \mathrm{~m}$,CO show highly similar estimates when compared to their approach. As a test gas, NO has the advantage that it binds much better to $\mathrm{Hb}$ than $\mathrm{CO}$ does, in fact so good that $R$ cap can be set at zero. This relieves the researcher from estimating $\theta \mathrm{CO}$ because it is very large, and the term $1 / \theta \mathrm{CO} Q \mathrm{c}$ becomes zero. MoINARD and Guenard [14] derived equations to obtain $1 / Q \mathrm{c}$ and $1 / T \mathrm{~m}, \mathrm{CO}$ using the single-breath NO-CO diffusing capacity approach and compared the outcome to the classical approach of Roughton and Forster [1]. The first method is not hampered by estimating $\theta \mathrm{CO}$ and the two methods produce similar values: $Q_{\mathrm{c}}$ was $85.5 \pm$ $17 \mathrm{~mL}$ for the NO-CO method and $81.9 \pm 14.5 \mathrm{~mL}$ for the Roughton and Forster approach. Therefore, this must mean that the current estimates of $\theta \mathrm{CO}$ are not altogether highly flawed.

In summary, the authors have determined new reference equations for $1 / Q_{\mathrm{c}}$ and $1 / T \mathrm{~m}, \mathrm{CO}$, which show similar relationships with height, age and $1 / Q_{c}$ and $1 / T \mathrm{~m}, \mathrm{CO}$ as previous ones. The major differences are the lower residual standard deviations.

Acknowledgements. Without the help of the Pulmonary Function Laboratory this study could not have been accomplished. The authors thank K. Hol-Eras, A. van Vliet-Klever, and H. van Zantwijk-Biljard.

\section{References}

1. Roughton FJW, Forster RE. Relative importance of diffusion and chemical reaction rates in determining rate of exchanges of gases in the human lung with special reference to true diffusing capacity of pulmonary membrane and blood volume in the lung capillaries. J Appl Physiol 1957; 11: 290-302.

2. Steenhuis LH, Groen HJM, Koëter GH, van der Mark ThW. Diffusion capacity and haemodynamics in primary and chronic thromboembolic pulmonary hypertension. Eur Respir J 2000; 16: 276-280.

3. Cotes JE. Lung Function, Assessment and Application in Medicine. 5th Edn. Oxford, Blackwell Scientific Publications, 1993; pp. 445-514.

4. Frans A. Les valeurs nomales du volume capillaire pulmonaire $(\mathrm{Vc})$ et de la capacité de diffusion de la membrane alveolo-capillaire. In: Arcangeli $\mathrm{P}$, ed. Normal Values for Respiratory Function in Man. Torino, Panminerva Medica, 1970; pp. 352-363.

5. Crapo RO, Moris AH, Gardner RM. Reference values for pulmonary tissue volume, membrane diffusing capacity and pulmonary capillary blood volume. Bull Eur Physiopathol Respir 1982; 18: 893-899.

6. Miller WF, Scacci R, Gast LR. Laboratory Evaluation of Pulmonary Function. Philadelphia, JB Lippencott, 1987.

7. Rothen HU, Sporre B, Engberg G, Wegenius G, Reber A, Hedenstierna G. Prevention of atelectasis during general anaesthesia. Lancet 1995; 345: $1387-$ 1391.

8. Stam H, Hrachovina V, Stijnen T, Versprille A. Diffusing capacity dependent on lung volume and age in normal subjects. J Appl Physiol 1994; 76: 2356 2363.

9. Quanjer PH, Tammeling GJ, Cotes JE, Pedersen OF, Peslin R, Yernault J-C. Lung volumes and forced ventilatory flows. Eur Respir J 1993; 6: Suppl. 16, s5s40.

10. Stevens J. Applied Multivariate Statistics for the Social Sciences. New Jersey, L. Erlbaum Ass., 1996.

11. Chinn DJ, Cotes JE, Flowers R, Marks A-M, Reed JW. Transfer factor (diffusing capacity) standardized for alveolar volume: validation, reference values and applications of a new linear model to replace $K \mathrm{CO}(T \mathrm{~L} /$ VA). Eur Respir J 1996; 9: 1269-1277.

12. Hughes JMB, Pride NB. In defence of the carbon monoxide transfer coefficient KCO (TL/VA). Eur Respir J 2001; 17: 168-174.

13. Forster RE. The single breath carbon monoxide transfer test 25 years on: a reappraisal. Thorax 1983; 38: $1-5$.

14. Moinard J, Guenard H. Determination of lung capillary blood volume and membrane diffusing capacity in patients with COLD using the NO-CO method. Eur Respir J 1990; 3: 318-322. 